\title{
Incarcerated Inguinal Hernia: A Cause of Testicular Ischemia Without the 'Twist'
}

\author{
Divya Singh', Ladbans Kaur', Neha Khanduja² \\ 'Department of Radiology, Prime Diagnostic Centre, Chandigarh, India \\ Indira Gandhi Medical College and Hospital, Shimla, India
}

Cite this article as: Singh D, Kaur L, Khanduja N. Incarcerated Inguinal Hernia: A Cause of Testicular Ischemia Without the 'Twist'. J Emerg Med Case Rep 2017; 8: 80-1.

\begin{abstract}
Introduction: Acute scrotal pain is a common complaint encountered in the emergency room. Besides testicular torsion, incarcerated inguinal hernia is another important cause that requires urgent exclusion as it warrants emergency surgery.

Case Report: Here we present a case of acute painful scrotal swelling in a young man owing to an incarcerated inguinal hernia that caused testicular ischemia. Ultrasound evaluation revealed the presence of bowel and omentum in the scrotum and normal echotexture of the testis. However, color Doppler revealed the absence of testicular blood flow. The patient underwent emergency surgery. The bowel and testis were salvaged by reducing the hernia.

Conclusion: This case report illustrates the occurrence of testicular ischemia owing to compressed vascular supply by an incarcerated inguinal hernia. It also shows that testicular ischemia can occur in the absence of a twisted spermatic cord, thereby underscoring the requirement for evaluating the testis in the setting of an incarcerated inguinal hernia.
\end{abstract}

Keywords: Incarcerated inguinal hernia, ultrasound, testis, ischemia.

Received: 12.04.2017 Accepted: 25.05.2017 Available Online Date: 25.08.2017

\section{Introduction}

Acute scrotal pain and swelling are common presentations in the emergency room (ER). The etiology of acute scrotum is diverse, namely ischemia (testicular or appendiceal torsion), infection (epididymo-orchitis, abscess, Fournier's gangrene), inflammation (Henoch-Schonlein purpura of scrotal wall and fat necrosis), trauma, and hernia (1). Accurate history and physical examinations usually help define the condition. Imaging examinations complement the clinical judgment in equivocal cases. Among all the abovementioned conditions, testicular ischemia requires the most expeditious diagnosis because time is crucial for salvaging the testis from irreversible damage. Here we present a case of testicular ischemia in a patient with an incarcerated inguinal hernia.

\section{Case report}

A 25-year-old man presented to the ER with a painful lump in the right scrotal region for one day. The onset was sudden. The patient was passing flatus and stool. There was no significant medical or family history. His vital signs were stable. Physical examination revealed a firm, tender swelling in the groin and scrotum on the right side. The right testis was not separately palpable. The lump was irreducible. The abdomen of the patient was soft on palpation. Ultrasonogram was performed to evaluate the lump and delineate the right testis. It revealed the presence of omentum and a bowel loop in the inguinoscrotal region (Figure 1a). The bowel wall showed a normal echo pattern. The right testis was visualized and had a normal size and echo pattern. Color Doppler evaluation of the right testis revealed an absence of blood flow, although the left testis had normal blood flow

Address for Correspondence:

Divya Singh, Prime Diagnostic Centre, Radiology, Chandigarh, India

E-mail: docdivyas@yahoo.co.in

(c) Copyright 2017 by Emergency Physicians Association of Turkey - Available online at www.jemcr.org 

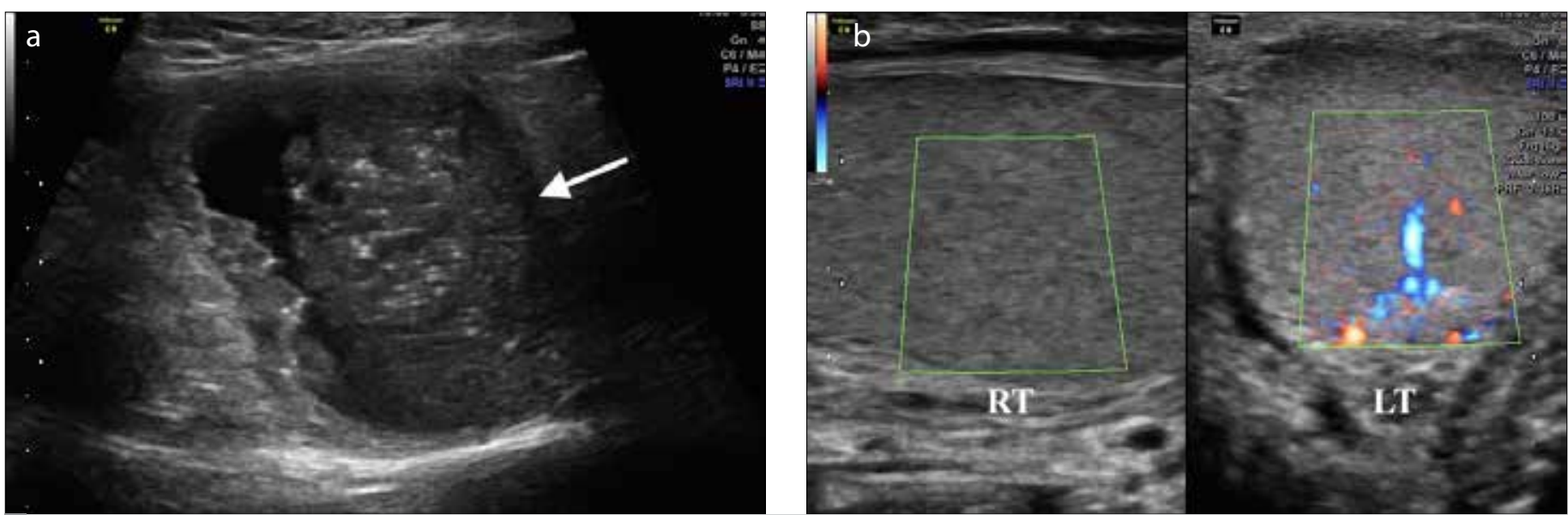

FIGURE 1. a, b. Incarcerated inguinal hernia. B-mode ultrasound of the scrotal swelling shows a small bowel loop (arrow) that contains food residue in the scrotum (a). Right testicular ischemia. Power Doppler sonogram of both testes reveals the absence of blood flow in the right (RT) testis and normal flow in the left (LT) testis (b)

(Figure 1b). Hence, a diagnosis of incarcerated right inguinal hernia with right testicular ischemia was made. The patient was transferred to the operating room where the inguinal hernia was reduced. The bowel and right testicle were found to be normal without any evidence of necrosis. The postoperative period was uneventful. Written informed consent was obtained from the patient.

\section{Discussion}

Acute scrotum is a common presentation in the ER and can be attributed to several causes.

Testicular torsion that leads to testicular ischemia is the most common cause and requires immediate exclusion because timely surgery can salvage the testis. Accurate history and meticulous physical examinations frequently help in the diagnosis. However, imaging examination has a complementary role in equivocal cases. Color Doppler ultrasound is an imaging modality of choice for diagnosing testicular ischemia (2). It is a widely available, noninvasive tool that can be used in the ER. Our case illustrates the occurrence of testicular ischemia owing to an incarcerated inguinal hernia. This condition has been extensively described in the pediatric literature (3-5). However, its description in adults is limited to a few case reports $(6,7)$.

In case of an incarcerated inguinal hernia, testicular ischemia occurs owing to a compressed spermatic cord by the hernia sac and not by a twisted spermatic cord, as observed in testicular torsion. Mechanical venous obstruction occurs owing to a compressed cord by a hernia, leading to the swelling of the cord from the internal inguinal ring outward toward the testis. If left unattended, venous thrombosis and hemorrhage occur. Tissue swelling and increased pressure within the tunica albuginea can ultimately lead to arterial insufficiency (8). This case report highlights the risk of testicular ischemia owing to an incarcerated inguinal hernia. Timely detection and prompt management in our case salvaged the testis and bowel.

\section{Conclusion}

It is imperative to increase the field of view in a patient with an incarcerated inguinal hernia and to evaluate the testis. Ultrasound examination should include both gray scale and color Doppler for assessing testicular blood flow.

Informed Consent: Written informed consent was obtained from patients who participated in this study.

Peer-review: Externally peer-reviewed.

Author Contributions: Concept - D.S., L.K., N.K.; Design - D.S., L.K., N.K.; Supervision - D.S.; Resources - L.K.; Materials - N.K.; Data Collection and/or Processing - D.S.; Analysis and/or Interpretation - D.S.; Literature Search - D.S., L.K., N.K.; Writing Manuscript - D.S., L.K., N.K.; Critical Review - D.S., L.K., N.K.

Conflict of Interest: No conflict of interest was declared by the authors.

Financial Disclosure: The authors declared that this study has received no financial support.

\section{References}

1. Dogra V, Bhatt S. Acute painful scrotum. Radiol Clin North Am 2004; 42 349-63. [CrossRef]

2. Wright $\mathrm{S}$, Hoffmann B. Emergency ultrasound of acute scrotal pain. Eur J Emerg Med 2015; 22: 2-9. [CrossRef]

3. Orth RC, Towbin AJ. Acute testicular ischemia caused by incarcerated inguinal hernia. Pediatr Radiol 2012; 42: 196-200. [CrossRef]

4. McGurk MN. Testicular infarction with incarcerated inguinal hernia in infants. N Z Med J 1978; 88: 14

5. Alyami F, Whelan T. Incarcerated inguinal hernia in infancy associated with testicular infarction: Case report and review of the literature. Can Urol Assoc J 2013; 7: E367-9. [CrossRef]

6. Desai $Y$, Tollefson B, Mills $L$, Galli R. Testicle ischemia resulting from an inguinal hernia. J Emerg Med 2012; 43: e299-301. [CrossRef]

7. Eutermoser M1, Nordenholz K. Testicular Compromise due to Inguinal Hernia. West J Emerg Med 2012; 13: 131-2. [CrossRef]

8. Hill MR, Pollock WF, Sprong DH. Testicular Infarction and Incarcerated Inguinal Herniae. Arch Surg 1962; 85: 351-4. [CrossRef] 